\title{
‘Chlorophyll-like' compounds as novel biomarkers of stress in corals
}

\author{
K. E. McDougall ${ }^{1, *}$, S. W. Gibb ${ }^{1}$, K. G. Boyd ${ }^{1}$, B. E. Brown ${ }^{1,2}$ \\ ${ }^{1}$ Environmental Research Institute, North Highland College, UHI Millennium Institute, Castle Street, Thurso, \\ Caithness KW14 7JD, UK \\ ${ }^{2}$ School of Biology, University of Newcastle, Newcastle upon Tyne NE1 7RU, UK
}

\begin{abstract}
The appearance of 'bleached' or pale-coloured corals at numerous locations around the world over the last 3 decades has been linked to various environmental stressors. However, the role and fate of zooxanthellar pigments in response to such stress has received little attention. We provide new insights into the adaptive response of coral zooxanthellae to environmental stress, based upon the analysis of chlorophyll pigments using high performance liquid chromatography. Manipulative field experiments were used to monitor induction and recovery of the reef coral Goniastrea aspera from photo-damage. Over a $6 \mathrm{~d}$ period the production of up to 6 compounds with very similar light absorbance spectra to chlorophyll a ( $\mathrm{chl} \mathrm{a}$ ) was observed. Higher concentrations of a sub-set of these products were observed in response to elevated solar radiation levels. The fact that the same chl a-like compounds were consistently observed under the same experimental conditions means that they may have significant potential as biomarkers of stress in corals and may also provide a means of 'fingerprinting' environmental stress in corals.
\end{abstract}

KEY WORDS: Coral bleaching $\cdot$ Stress biomarkers $\cdot$ Symbiotic algae $\cdot$ Chlorophyll a $\cdot$ HPLC

\section{INTRODUCTION}

Since the early 1980s 'bleached' or pale-coloured corals have been observed at numerous locations around the world (Glynn 1984). The concern expressed over bleaching has resulted in extensive studies of the processes involved. The bleaching of corals has now been linked to various environmental stressors, including elevated and reduced temperature (HoeghGuldberg \& Smith 1989, Glynn 1993, Coles \& Fadalallah 1991, Muscatine et al. 1991), elevated visible and ultraviolet light levels (Hoegh-Guldberg \& Smith 1989, Lesser et al. 1990, Kinzie 1993), combined light deprivation and starvation (Yonge \& Nicholls 1931), low salinity (Goreau 1964, Fang 1995) and bacterial infection (Kushmaro et al. 1996, Ben-Haim et al. 1999).

It is now evident that corals exhibit a range of pathological and physiological responses to environmental pressures depending on the degree or type of stress to which they are exposed. These range from more obvious and easily quantified responses, such as the loss of zooxanthellae, to more subtle changes in the host and symbiont, such as increased expressions of heat-shock proteins and antioxidant enzymes (Downs et al. 2000). The ability to measure responses under subtle levels of stress could be exploited to detect changes in biomarkers preceding 'bleaching' events, to provide a valuable tool to both marine scientists and coastal zone managers.

The loss of zooxanthellae (and their pigments) has long been established as a signal of stress in cnidarians (Yonge \& Nicholls 1931, Brown \& Howard 1985). Nevertheless, despite the focus on coral bleaching research in the last 2 decades (see Hoegh-Guldberg 1999, for review), there has been surprisingly little attention paid to coral algal pigments, either with respect to their involvement in the physiological mechanism of bleaching (Ambarsari et al. 1997) or their potential value as bio-indicators of stress.

Coral pigmentation, in particular chlorophyll a (chl a) content, is frequently determined by long established spectrophotometric or fluorometric methods 
(e.g. Holm-Hansen et al. 1965, Lorenzen 1967). However, these methods, which have traditionally been used in the characterisation of phytoplankton pigmentation, are prone to inaccuracies associated with the spectral interference of other chlorophylls (e.g. chlorophyll $b$ ), carotenoids, or from chl a degradation products (e.g. chlorophyllides, phaeophytins). The use of high performance liquid chromatography (HPLC) in conjunction with spectrophotometric or fluorescence detectors allows the rapid separation and more accurate quantitation of a wide range of chlorophyll and carotenoid pigments to be achieved (Wright et al. 1991, Ambarsari et al. 1997, Jeffrey et al. 1997). While these techniques are commonly used to provide estimates of phytoplankton abundance and insights into population composition, their application to coral studies has been limited.

In the present work we exploited HPLC with photodiode array detection to provide evidence of a subtle stress response in the symbiotic zooxanthellae of coral. This response would not be discernable through the application of conventional spectrophotometric or fluorometric techniques. We report the identification of 6 chl a-like compounds, which may be potential bioindicators of low-level stress in the zooxanthellae of the coral Goniastrea aspera. This response was rapid and recoverable and may be indicative of a novel mechanism involved in the adjustment of corals to environmental stress.

\section{MATERIALS AND METHODS}

Study site. Experiments were carried out on colonies of the shallow water coral species Goniastrea aspera in Phuket, Thailand $\left(7^{\circ} 50^{\prime} \mathrm{N}, 98^{\circ} 25.5^{\prime} \mathrm{E}\right)$, during November 2000. Factors responsible for solar bleaching and the temporal progression of bleaching in corals at the site have been described in detail by Brown et al. (1994) and Le Tissier \& Brown (1996). Notably, west faces of corals are exposed to higher incident solar radiation than east faces. As such, rotation of coral colonies from east to west is proposed to induce light stress and rotation from west to east to allow recovery from light stress.

Rotation experiments. Coral colonies of approximately $20 \mathrm{~cm}$ in diameter were carefully detached from the reef using a hammer and stone-chisel and rotated $180^{\circ}$ before being cemented in their new position. Additional colonies were detached from the reef and then replaced in their original position to act as handling controls. All colonies were tagged for future identification. As a result of the manipulation, former east surfaces now faced west and vice versa in rotated colonies. In this discussion, samples from corals rotated from the west to east sides will be denoted ' $W \rightarrow E^{\prime}$ and those rotated from east to west as ' $\mathrm{E} \rightarrow \mathrm{W}$ '. Samples from the east and west control or non-manipulated corals will be denoted as ' $\mathrm{E}_{\text {cont }}$ ' and ' $\mathrm{W}_{\text {cont }}$ ', respectively.

Sample collection and preparation. Cores $(25 \mathrm{~mm}$ diameter) were removed from east and west sides of 5 coral colonies from each of the above conditions using methodology previously described (Brown et al. 1999a). Baseline cores were taken at the beginning of a neap tide sequence at the time of manipulation on 13 November 2000. Experimental cores were collected at 2, 4 and $6 \mathrm{~d}$ after the corals were aerially exposed on the subsequent low spring tide sequence $(23,25$ and 27 November).

After collection in the field, the cores were taken, in darkened containers on ice, back to the laboratory where they were frozen at $-50^{\circ} \mathrm{C}$ within $30 \mathrm{~min}$ of sampling. Algal pellets were prepared as described by Ambarsari et al. (1997). Briefly, tissue was removed from coral cores by air gunning to produce algal pellets, which were stored under liquid nitrogen prior to transportation to the UK for subsequent studies.

In the laboratory, algal pellets were homogenised in buffer (Tris-HCl, $10 \mathrm{mN}$ ) and a sub-sample was stored for the determination of cell numbers. Pigments were extracted from the remaining homogenate using methanol with the aid of ultrasonication. Extracts were clarified using centrifugation (5 min at $1800 \times g$ ), and the supernatant was drawn off by micro-syringe for analysis by HPLC.

Pigments were analysed by the method of Barlow et al. (1997), modified as described in Brown et al. (2002a). In brief, aliquots of the clarified extract were loaded into the autosampler and maintained at $2{ }^{\circ} \mathrm{C}$ before being vortex-mixed with $1 \mathrm{M}$ ammonium acetate buffer $(1: 1, \mathrm{v} / \mathrm{v})$. Buffered extracts were injected $(100 \mu \mathrm{l})$ onto a Hypersil MOS2 C-8 column (3 $\mathrm{m}$ particle size, $100 \times 4.6 \mathrm{~mm}$ ) maintained at $30^{\circ} \mathrm{C}$. Pigments were separated using a binary mobile phase system (min; 70:30 [v/v] methanol:1.0 M ammonium acetate; $100 \%$ methanol $):(0 ; 100 ; 0),(2 ; 50 ; 50),(12 ; 30$; $70),(25 ; 10 ; 90),(27 ; 0 ; 100),(29 ; 0 ; 100),(29.1 ; 0 ; 100)$, $(35 ; 0 ; 100)$. Flow rate was constant at $0.85 \mathrm{ml} \mathrm{min}^{-1}$.

The analyses were performed using an integrated Thermo-Separations HPLC system comprising: SCM1000 vacuum degasser, P4000 quaternary pump, AS3000 auto-sampler (with sample tray cooling, column over and sample preparation capability) and UV6000LP diode array detector (DAD). System control, data collection and integration were performed using Chromquest software.

Pigment identity was secured through co-elution with authentic pigments obtained from either Sigma Aldrich or from DHI. Confirmation of analyte identity 
was achieved through spectral comparison of DAD data to standards using the Chromquest software. Quantification of pigments was carried out at $444 \mathrm{~nm}$.

Algal cell counts from pigment subsamples were obtained using a Neubauer haemocytometer and by following established techniques (Brown et al. 1999a). Pigment concentrations were then calculated as femtomoles cell ${ }^{-1}$.

Data analysis. Compounds were identified as 'chl a-like' by their proximity to chl a on the HPLC chromatogram and their spectral similarity to chl a determined using the Chromquest software. These compounds were quantified by peak area and denoted by their retention time relative to chl a itself.

Statistical comparisons were carried out to compare the concentration of chl a-like compounds, chl a itself and the total chl a pool, i.e. chl a plus chl a-like compounds (total chl a), between control and rotated cores.

\section{RESULTS}

Analysis of algal pellets from the coral Goniastrea aspera by HPLC with DAD revealed the presence of a range of chlorophyll and carotenoid pigments, principally chlorophyll $c_{2}$, chl $a$, peridinin, diadinoxanthin, diatoxanthin and $\beta$-carotene (Fig. 1a). This pigment signature is characteristic of zooxanthellae and has been reported previously (Kleppel et al. 1989, Ambarsari et al. 1997).

More detailed examination of the chromatograms revealed the presence of a number of additional peaks in the time window around chl a. A total of 6 discrete compounds were identified from the samples analysed, all exhibiting characteristic chlorophyll-like absorbance spectra, with blue spectral bands at 418 to $434 \mathrm{~nm}$ and red spectral bands at 654 to $662 \mathrm{~nm}$ (Figs. 1b \& 2). The retention times of these chl a-like compounds relative to that of chl a were consistent in all samples analysed (Table 1; with 1 exception, which was excluded from further analyses). While chromatographic retention times were highly reproducible, the integrated peak area (and by inference their concentration) showed some variability (Fig. 3).

Data from rotated cores was compared to that from controls in order to study the initial response to the increase $(\mathrm{E} \rightarrow \mathrm{W})$ or decrease $(\mathrm{W} \rightarrow \mathrm{E})$ of light stress (e.g. $\mathrm{W} \rightarrow \mathrm{E}$ compared with $\mathrm{W}_{\text {cont }}$ and with $\mathrm{E}_{\text {cont }}$ ).

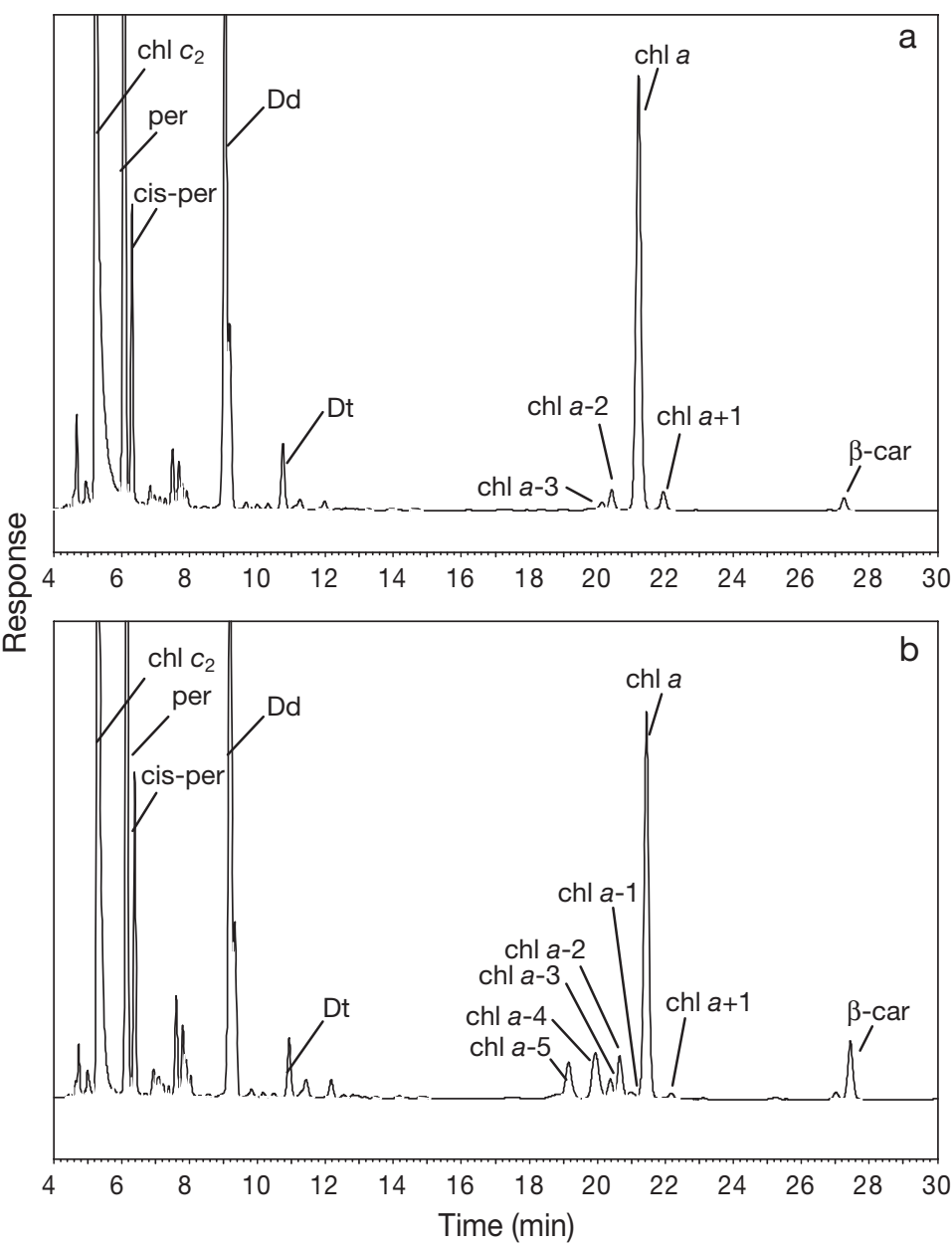

Fig. 1. Representative chromatograms illustrating the peaks corresponding to the chl a-like compounds in (a) a control sample showing the chl a peak with few additional peaks and (b) a rotated sample $(\mathrm{E} \rightarrow \mathrm{W})$ with a greater number of peaks (chl $a$ : chlorophyll $a_{\text {; }}$ chl $a \pm x$ : chlorophyll $a$ like compounds). The other major pigment peaks denoted are chlorophyll $C_{2}$ (chl $C_{2}$ ), peridinin (per), cis-peridinin (cis-per), diadinoxanthin (Dd), diatoxanthin (Dt) and $\beta$-carotene $(\beta$-car)

Statistical comparison between experimental conditions showed that there was no significant difference in the concentration of chl a-like compounds between $\mathrm{E}_{\text {cont }}$ and $\mathrm{W}_{\text {cont }}$ cores throughout the $6 \mathrm{~d}$ experiment. There was also no significant difference between $\mathrm{W} \rightarrow \mathrm{E}$ cores and $\mathrm{W}_{\text {cont }}$ cores. However, there was a significant increase in the concentration of chl a-like compounds between $\mathrm{E} \rightarrow \mathrm{W}$ cores and $\mathrm{E}_{\text {cont }}$ cores at Day 2, but no significant difference thereafter (Fig. 4a). This indicates an initial increase in chl a-like compounds in response to the increased solar radiation stress on the west side of the corals, followed by adaptation by Days 4 and 6.

There was no significant difference in chl a concentration between rotated cores and the side of origin $\left(\mathrm{E} \rightarrow \mathrm{W}\right.$ and $\mathrm{E}_{\text {cont }}, \mathrm{W} \rightarrow \mathrm{E}$ and $\left.\mathrm{W}_{\text {cont }}\right)$ at Day 2, indicating 
Table 1. Retention time (RT) and frequency of occurrence of chl a-like compounds relative to chl a

\begin{tabular}{|lccccccc|}
\hline & Chl $a-5$ & Chl $a-4$ & Chl $a-3$ & Chl $a-2$ & Chl $a-1$ & Chl $a$ & Chl $a+1$ \\
\hline Mean RT relative to chl a (min) & -2.26 & -1.47 & -1.06 & -0.78 & -0.46 & 0.00 \\
SD & 0.032 & 0.024 & 0.008 & 0.004 & 0.007 & 0.000 \\
Occurrence (\% samples analysed) & 72 & 74 & 100 & 100 & 47 & 100 & 0.003 \\
& & & & & & 100 \\
\hline
\end{tabular}

that chl a was conserved upon rotation (Fig. 4b). There was also no significant difference in chl a concentration between $E_{\text {cont }}$ and $W_{\text {cont }}$ cores. As such, the increase in the concentration of total chl $a$ in $\mathrm{E} \rightarrow \mathrm{W}$ cores compared with $\mathrm{E}_{\text {cont }}$ cores at Day 2 (Fig. 4c) reflected the conservation of $\mathrm{chl} a$ and the increase in chl a-like compounds.

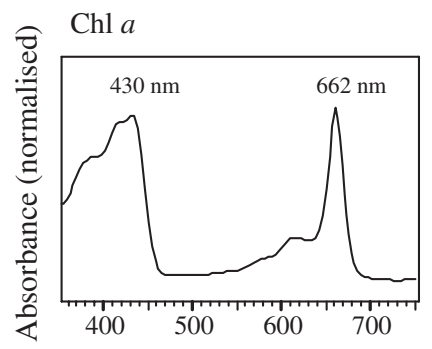

Chl $a-5$

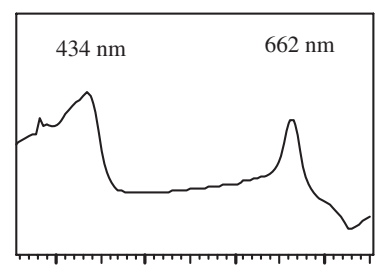

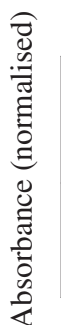

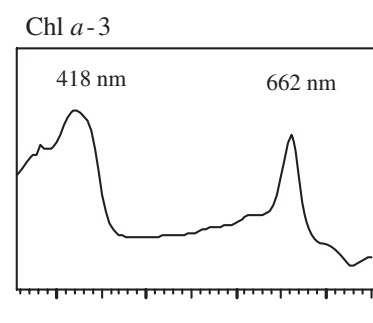

Chl $a-1$

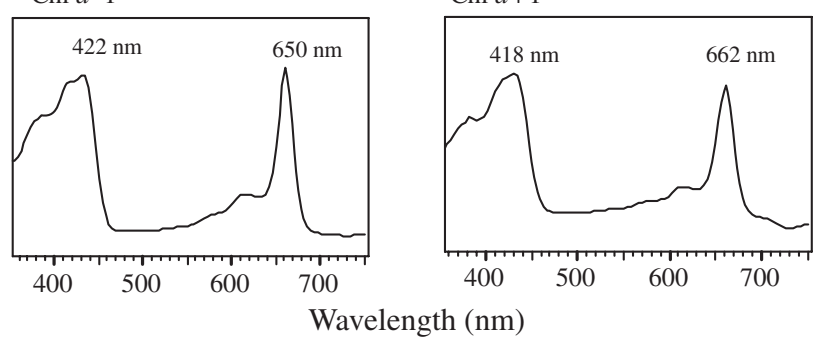

Fig. 2. Light absorbance spectra of chl a and the chl a-like compounds (chl $a \pm x$ )
This increase in the concentration of chl a-like compounds on rotation $\mathrm{E} \rightarrow \mathrm{W}$ at Day 2 was associated with an increase in a specific set of compounds (chl a-5 to -1) eluting at retention times prior to chl a (Fig. 5).

\section{DISCUSSION}

\section{Pigment identity}

The ubiquity of chl a in phytoplankton has long been recognised, and this pigment is routinely used as a proxy of phyto-biomass in oceanographic studies. Traditionally, algorithms based on spectrophotometric and fluorometric measurements have been used to quantify chl a in bulk extracts of phytoplankton. However, inaccuracies in such methodologies, arising from the spectral interference of other chlorophyll compounds (e.g. chlorophyll b), chlorophyll transformation products (e.g. phaeophorbides, chlorophyllides, phaeophytins) and/or carotenoids has led to the development and application of HPLC-based methodologies allowing more accurate estimates of chl a from phytoplankton extracts. The continued development of HPLC methodologies now allows the identification and quantification of $>50$ individual pigments from phytoplankton extracts (Jeffrey et al. 1997).

Despite the advances in the application of HPLC in studies of oceanic phytoplankton, the study of algal pigmentation in corals has, to a great extent, been neglected. Exceptions include the analysis of chlorophylls $a$ and $c$ and the carotenoids diadinoxanthin and diatoxanthin (Kleppel et al. 1989, Brown et al. 1999a, 2000a, 2002a). Phaeophytin a and pyrophaeophytin a have also been identified as breakdown products of chlorophyll during coral bleaching (Ambarsari et al. 1997).

The present work reported results from the analysis of pigments in a manipulative field experiment designed to study the effect of solar stress on corals (specifically Goniastrea aspera). Previous studies at the reef site (Brown et al. 1994, 2000a) have shown that western surfaces of intertidal coral colonies are exposed to higher levels of solar irradiance than eastern surfaces during spring tide exposures. This obser- 


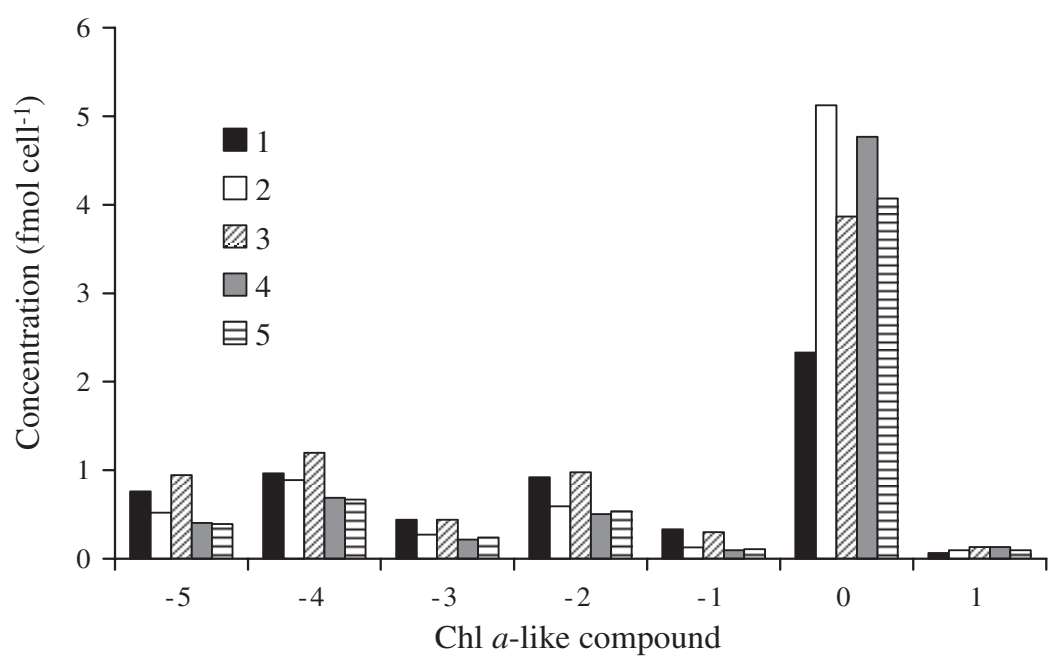

Fig. 3. Concentration of chl a-like compounds for 5 replicate samples (1 to 5) relative to $\mathrm{chl} a$ in the data set of $\mathrm{E} \rightarrow \mathrm{W}$ cores at Day 2. Bars represent individual samples

vation was exploited in manipulative field experiments to investigate induction of photo-damage upon rotation of coral cores $180^{\circ}$ from east to west and recovery from photo-damage upon rotation from west to east (Brown et al. 2000a).

Pigment analysis of zooxanthellae sampled during the experiment revealed the presence of up to $6 \mathrm{com}$ pounds eluting in the region of chl a. Transformation products of other key coral pigments including chlorophyll $c$ and peridinin were not detected. As seen from Table 1, the occurrence of these chl a-like compounds was consistent. From their retention time data and spectral absorbance characteristics (Table 1, Figs. 1 \& 2 ), we ascertained that these compounds do not include commonly proposed chl a transformation products, such as chlorophyllide, pyro-phaeophorbide, phaeophorbide (which would have eluted with shorter retention times than chl a), phaeophytin, or sterol chlorin esters of phaeophorbide (which would have longer retention times).

On the basis of retention time, divinyl chlorophyll a is a candidate for one of the chl a-like compounds that elute ahead of chl a. This pigment is used as a highly specific indicator of the prokaryotic picoplankton, prochlorophytes (Chisholm et al. 1988). Similarly, phytylated chl $c$-like pigments, associated with many prymnesiophyte species (Jeffrey et al. 1997), have been reported to elute in the proximity of chl a under reverse-phase HPLC conditions. However, the absorbance characteristics of these compounds eliminate both as potential candidates for the chl a-like compounds described here.

It is likely that chl a epimers and allomers are included among the compounds identified. The fact that reverse-phase HPLC was used in the analysis and that most of the compounds elute ahead of chl a sug- gests that they are of lower molecular weight and/or more polar than chl a itself. The absorbance spectra shown in Fig. 2 also suggest that the porphyrin ring system is intact. Candidate compounds could therefore include chlorophyll-like compounds with oxidatively modified phytyl side chains. The oxidation of free phytol is known to produce more polar species, which have been observed in environmental samples (Rontani \& Aubert 2005).

At present we are only able to speculate over the likely identity of these chl a-like compounds and to eliminate a range of commonly studied chl a transformation products. However, only by the utilisation of HPLC was 


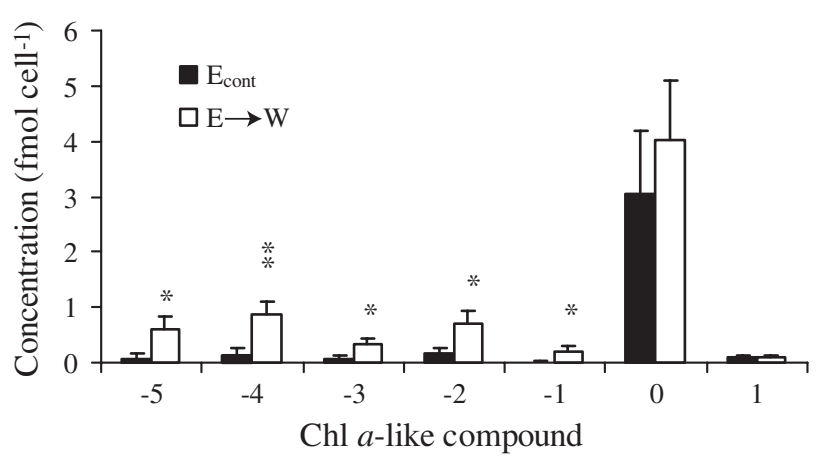

Fig. 5. Concentration of chl a-like compounds for $\mathrm{E} \rightarrow \mathrm{W}$ cores compared with $\mathrm{E}_{\text {cont }}$ cores at Day 2. Bars represent mean values (error bars: $+\mathrm{SD}$ ); ${ }^{*} \mathrm{p}<0.05,{ }^{* *} \mathrm{p}<0.01$ compared with $\mathrm{E}_{\text {cont }}$ as determined by paired 2-tailed $t$-test

the presence of these compounds revealed. Had spectrophotometric or fluorometric tools (which could not differentiate between $\mathrm{chl} a$ and the chl $a$-like compounds) been employed, this subtle expression of pigments would not have been observed. Further studies utilising mass spectrometric detection will be required to elucidate the structures of these chl a-like compounds.

\section{Environmental factors}

Analysis of the evolution of the chl a-like compounds throughout the experiment shows that they are particularly prevalent on Day 2 in samples from coral faces that had been rotated $180^{\circ}$ from east to west $(E \rightarrow W)$. Although there was variation in the relative concentration of the compounds between sample replicates (resulting in high SDs), there was a significant increase in chl a-like compounds in response to increased solar radiation stress on Day 2. There was no significant difference between $\mathrm{E}_{\text {cont }}$ and $\mathrm{W}_{\text {cont }}$ indicating these samples were not under any increased stress. There was no significant change as the cores were moved to a lower irradiance level $(\mathrm{W} \rightarrow \mathrm{E})$.

By Day 4 there was no significant difference between $\mathrm{E}_{\text {cont, }}, \mathrm{W}_{\text {cont, }}$ or rotated samples, indicating that the $\mathrm{E} \rightarrow \mathrm{W}$ samples had adapted to the higher solar radiation conditions. This suggests that the increase in chl a-like compounds is associated with a phase in the photo-adaptation process of the coral zooxanthellae.

The increase in total chl $a$ in $\mathrm{E} \rightarrow \mathrm{W}$ samples may be attributed to an increase in chl a-like compounds and, specifically, a subset of compounds eluting prior to chl a. Notably there was no significant increase in the concentration of chl a itself.

Thus, it appears that there was an increase in chl alike compounds in response to increased levels of solar radiation stress, while the level of chl a itself was maintained. If these chl a-like compounds represent chl a breakdown, it is possible that there was an overall increase in chl a production to compensate for any degradation, thereby maintaining chl a levels. However, the nature of these products and the mechanism by which they are produced is currently unknown and warrants further investigation.

Previous studies have shown an increase in spectrophotometrically measured chlorophyll during a variety of stress events in both laboratory manipulations and bleaching events in the field (Fitt et al. 1993, Le Tissier \& Brown 1996, Jones 1997, Jones \& Steven 1997, Ambarsari 1998, Brown et al. 1999b, Brown et al. 2000b, Kerswell \& Jones 2003, Saxby et al. 2003, Bhagooli \& Yakovleva 2004, Yakovleva \& Hidaka 2004). Our results infer that this response, which has been attributed to an increase in chl $a$, may in fact be due to an increase in chl a-like compounds. Clearly, the application of HPLC to such studies and the ability to discretely resolve the individual compounds, which may collectively contribute to the spectrophotometric signal, is advantageous.

\section{Mechanism sensitivity}

Corals have been shown to be capable of acclimatisation and adaptation to environmental stress (for review see Coles \& Brown 2003). Brown et al. (2000b, $2002 \mathrm{~b}$ ) demonstrated that surfaces of corals that were acclimatised to elevated solar radiation subsequently showed improved temperature tolerance as a result of improved photoprotection in the algae and host defences. The time scale over which these defences operate may range from minutes (molecular responses) to days (loss of zooxanthellae) depending on the nature and degree of the stress.

The production of chl a-like compounds in response to the rotation occurs relatively rapidly (within $48 \mathrm{~h}$ ). Conditions at the study location in November are such that solar radiation levels are seasonally low, with corals having been exposed to the highest solar radiation during low tides in April. The rotation experiments are therefore associated with the induction of a low level of stress. As such, the production of the chl a-like compounds is a result of a minor stress and the fact that the levels of these compounds return to that of the control samples after $4 \mathrm{~d}$ suggests that the mechanism responsible for their formation is rapidly reversed or brought under control through acclimatisation to the stress conditions.

Previous studies (Brown et al. 2000a, 2002a) have demonstrated an increase in the ratio of the xanthophylls diadinoxanthin to diatoxanthin in response to 
solar radiation stress. In the present study, this response was not observed (data not shown). From this, it is possible to infer that the expression of chl a-like compounds may be a more sensitive response to lowlevel solar radiation stress than to xanthophyll cycling. However, the xanthophyll ratio is known to respond rapidly (hours) to changing PAR (photosynthetically active radiation) levels (Brown et al. 1999a), while the rate of the chl a response is as yet unknown (we report changes measured over a number of days). Therefore, it is possible that, while the change in xanthophyll ratio is a rapid response to the conditions experienced over a period of hours, the chl a response is a less rapid response reflecting the conditions experienced over a number of days. To resolve this issue, future, simultaneous study of both chl a transformation products and the xanthophylls is required, over a period of several days in response to varying PAR, but must incorporate a sampling frequency of 4 to $6 \mathrm{~h}$.

\section{CONCLUSIONS}

Through the application of HPLC with DAD we have identified the occurrence of a number of chl a-like compounds that are expressed by zooxanthellae in response to solar radiation manipulation. While the structures of these compounds were not determined, their occurrence is reproducible and consistent. Ongoing studies include the elucidation of mechanisms involved in the generation of these compounds and their structural characterisation.

The occurrence of these compounds was observed under conditions that did not induce a photoprotective response in xanthophyll cycling. They, therefore, have the potential to act as sensitive 'biomarkers' of subtle levels of environmental stress in the coral. Whether the analysis can be used as an early warning of the onset of 'bleaching' will require further verification.

Acknowledgements. The authors thank the director and staff of the Phuket Marine Biological Center, Thailand, for their continued support and also the Leverhulme Trust, UK, for financial support of B.E.B. The authors also acknowledge 3 anonymous referees who provided constructive reviews of this work.

\section{LITERATURE CITED}

Ambarsari I (1998) The nature and significance of pigments in the symbiotic algae of corals. PhD thesis, University of Newcastle upon Tyne

Ambarsari I, Brown BE, Barlow RG, Britton G, Cummings D (1997) Fluctuations in algal chlorophyll and carotenoid pigments during solar bleaching in the coral Goniastrea aspera at Phuket, Thailand. Mar Ecol Prog Ser 159: 303-307
Barlow RG, Cummings DG, Gibb SW (1997) Improved resolution of mono- and divinyl chlorophylls $a$ and $b$ and zeaxanthin and lutein in phytoplankton extracts using reverse phase C-8 HPLC. Mar Ecol Prog Ser 161:303-307

Ben-Haim Y, Banim E, Kushmaro A, Loya Y, Rosenberg E (1999) Inhibition of photosynthesis and bleaching of zooxanthellae by the coral pathogen Vibrio shiloi. Environ Microbiol 1:223-229

Bhagooli R, Yakovleva I (2004) Differential bleaching susceptibility and mortality patterns among four corals in response to thermal stress. Symbiosis 37:121-136

Brown BE, Howard LS (1985) Assessing the effects of 'stress' on reef corals. Adv Mar Biol 22:1-63

Brown BE, Dunne RP, Scoffin TP, Le Tissier MDA (1994) Solar damage in intertidal corals. Mar Ecol Prog Ser 105: 219-230

Brown BE, Ambarsari I, Warner ME, Fitt WK, Dunne RP, Gibb SW, Cummings DG (1999a) Diurnal changes in photochemical efficiency and xanthophyll concentrations in shallow water reef corals: evidence for photoinhibition and photoprotection. Coral Reefs 18:99-105

Brown BE, Dunne RP, Ambarsari I, Le Tissier MDA, Satapoomin U (1999b) Seasonal fluctuations in environmental factors and their influence on photophysiological parameters in four Indo-Pacific coral species from the Andaman Sea, Indian Ocean. Mar Ecol Prog Ser 191:53-69

Brown BE, Dunne RP, Warner ME, Ambarsari I, Fitt WK, Gibb SW, Cummings DG (2000a) Damage and recovery of Photosystem II during a manipulative field experiment on solar bleaching in the coral Goniastrea aspera. Mar Ecol Prog Ser 195:117-124

Brown BE, Dunne RP, Goodson MS, Douglas AE (2000b) Bleaching patterns in reef corals. Nature 404:142-143

Brown BE, Downs CA, Dunne RP, Gibb SW (2002a) Preliminary evidence for tissue retraction as a factor in photoprotection of corals incapable of xanthophyll cycling. J Exp Mar Biol Ecol 227:129-144

Brown BE, Downs CA, Dunne RP, Gibb SW (2002b) Exploring the basis of thermotolerance in the reef coral Goniastrea aspera. Mar Ecol Prog Ser 242:119-129

Chisholm SW, Olson RJ, Zettler ER, Goericke R, Waterbury JB, Welschmeyer NA (1988) A novel free-living prochlorophyte abundant in the oceanic euphotic zone. Nature 334: 340-343

Coles SL, Brown BE (2003) Coral bleaching-capacity for acclimatization and adaptation. Adv Mar Biol 46:183-223

Coles SL, Fadlallah YH (1991) Reef coral survival and mortality at low temperatures in the Arabian Gulf: new speciesspecific lower temperature limits. Coral Reefs 9:231-237

Downs CE, Mueller E, Phillips S, Fauth JE, Woodley CM (2000) A molecular biomarker system for assessing the health of coral (Montastrea faveolata) during heat stress. Mar Biotechnol 2:533-544

Fang L, Liao CW, Lin MC (1995) Pigment composition in different-coloured scleractinian corals before and during the bleaching process. Zool Stud 34:10-17

Fitt WK, Spero HJ, Halas J, White MW, Porte JW (1993) Recovery of the coral Montastrea annularis in the Florida Keys after the 1987 Caribbean 'bleaching event'. Coral Reefs 12:57-64

Glynn PW (1984) Widespread coral mortality and the 1982/1983 El Nino warming event. Environ Conserv 11:133-146

Glynn PW (1993) Coral-reef bleaching-ecological perspectives. Coral Reefs 12:1-17

Goreau TJ (1964) Mass expulsion of zooxanthellae from Jamaican reef communities after hurricane Flora. Science 145:383-386 
Hoegh-Guldberg O (1999) Climate change, coral bleaching and the future of the world's coral reefs. Mar Freshw Res 50:839-866

Hoegh-Guldberg O, Smith GJ (1989) The effect of sudden changes in temperature, light and salinity on the population density and export of zooxanthellae from the reef corals Stylophora pistillata Esper and Seriatopora hystrix Dana. J Exp Mar Biol Ecol 129:279-303

Holm-Hansen O, Lorenzen CJ, Holmes RW, Strickland JDH (1965) Fluorometric determination of chlorophyll. J Cons Int Explor Mer 301:3-15

Jeffrey SW, Mantoura RFC, Wright SW (eds) (1997) Phytoplankton pigments in oceanography: guidelines to modern methods. UNESCO monographs in oceanographic methods. Report for SCOR WH 78, SCOR-UNESCO, Paris

Jones RJ (1997) Changes in zooxanthellar densities and chlorophyll concentrations in corals during and after a bleaching event. Mar Ecol Prog Ser 158:51-59

Jones R, Steven AL (1997) Effects of cyanide on corals in relation to cyanide fishing on reefs. Mar Freshw Res 48: 517-522

Kerswell AP, Jones RJ (2003) Effects of hypo-osmosis on the coral Stylophora pistillata: nature and cause of 'low-salinity bleaching'. Mar Ecol Prog Ser 253:145-154

Kinzie RA III (1993) Effect of ambient levels of solar ultraviolet radiation on zooxanthellae and photosynthesis of the reef coral Montipora verrucosa. Mar Biol 116:319-327

Kleppel GS, Dodge RE, Reese CJ (1989) Changes in pigmentation associated with the bleaching of stony corals. Limnol Oceanogr 34:1331-1335

Kushmaro A, Loya Y, Fine M, Rosenberg M (1996) Bacterial infection and bleaching. Nature 380:396

Lesser MP, Stochaj WR, Tapley DW, Shick JM (1990) Bleach-

Editorial responsibility: Otto Kinne (Editor-in-Chief), Oldendorf/Luhe, Germany ing in coral reef anthozoans: effects of irradiance, ultraviolet radiation and temperature on the activities of protective enzymes against active oxygen. Coral Reefs 8: 225-232

Le Tissier MDA, Brown BE (1996) Dynamics of solar bleaching in the intertidal reef coral Goniastrea aspera at Ko Phuket. Mar Ecol Prog Ser 136:235-244

Lorenzen C (1967) Determination of chlorophyll and pheopigments: spectrophotometric equations. Limnol Oceanogr $12: 343$

Muscatine L, Grossman D, Doino J (1991) Release of symbiotic algae by tropical sea-anemones and corals after cold shock. Mar Ecol Prog Ser 77:233-243

Rontani JF, Aubert C (2005) Characterization of isomeric allylic diols resulting from chlorophyll phytyl side-chain photo- and autoxidation by electron ionization gas chromatography/mass spectrometry. Rapid Commun Mass Spectrom 19:637-646

Saxby T, Dennison WC, Hoegh-Guldberg O (2003) Photosynthetic responses of the coral Montipora digitata to cold temperature stress. Mar Ecol Prog Ser 248:85-97

Wright SW, Jeffrey SW, Mantoura RFC, Llewellyn CA, Bjornland T, Repeta D, Welsch-Meyer N (1991) Improved HPLC method for the analysis of chlorophylls and carotenoids from marine phytoplankton. Mar Ecol Prog Ser 77: 183-196

Yakovleva I, Hidaka M (2004) Different effects of high temperature acclimation on bleaching-susceptible and tolerant corals. Symbiosis 37:87-105

Yonge CM, Nicholls AG (1931) Studies on the physiology of corals. V. The effects of starvation in light and in darkness on the relationship between corals and zooxanthellae. Sci Rep Gt Barrier Reef Exped 1928-29 1:176-211

Submitted: October 27, 2005; Accepted: March 29, 2006

Proofs received from author(s): October 4, 2006 